\title{
Understanding Mathematics Classroom Teaching: Hermeneutics Inquiry
}

\author{
Xiong Wang \\ Correspondence: Xiong Wang, Department of Secondary Education, University of Alberta, 116 St. and 85 Ave., \\ Edmonton, AB, T6G 2R3, Canada
}

Received: June 26, 2015 Accepted: July 13, $2015 \quad$ Online Published: July 15, 2015

doi:10.11114/jets.v3i5.951

URL: http://dx.doi.org/10.11114/jets.v3i5.951

\begin{abstract}
In order to understand meaning of mathematics classroom teaching, this paper uses narrative to present the meaning through hermeneutics inquiry from the author's research experiences. There are two threads in the research experience: research on classroom teaching and students' understanding in classroom teaching. The narrative provides not only a lived experience but a process for the action towards the essential meaning of students' learning through hermeneutics inquiry.
\end{abstract}

Keywords: classroom teaching; students' learning; hermeneutics

\section{Research on Classroom Teaching}

\subsection{Is Doing Research only for Publications?}

In 2008 when I graduated from the master program, I set about working while doing research on mathematics education in a Chinese university. Frankly speaking, my initial pursuit in doing research in Mathematics Education aimed to get my related articles publicized in certain journals. In fact, besides me, it is the same case to the majority of teachers or researchers of all kinds in Chinese mathematics education area. Especially in universities or academic research institutes, the teachers or researchers always try their best to find their ways to make their papers possibly published in prestigious journals because their promotion to the higher levels of positions such as Professor or others related is heavily reliant upon the quantity and quality of their publications according to the rules or regulations from different university academic committees. Generally, at that time, two recognized ways were welcome in Chinese mathematics education area as feasibility to get the articles publicized. One way was to introduce new theories or ideas of education into China, the other was to implement new theories or ideas in practice. Thus, I was wondering whether or not it would be enough for the researchers to do researches only for publications rather than for practices in education. For me, it was clear that I did not want to be such kind of scholar from the bottom of my heart because I believed that it would not make sense in doing education research without considering the conditions of local socio-cultures and students in practices.

\subsection{Research Orientation}

In 2010 after two-year trial of writing articles only for publication, I decided to identify my own research direction in mathematics education. Considering the real context of mathematics education in daily classroom teaching, I was determined to start with my research on the authentic classroom teaching. As a matter of fact, at that time, there existed a dilemma in Chinese mathematics education that the scholars from the other parts of world thought Chinese students learned mathematics in very rote ways such as memorizing and practicing a lot while Chinese students' outstanding performances demonstrated a deep understanding of knowledge in international mathematics test (Fan et al., 2004). This triggered me to establish a research orientation of finding out the way that Chinese students learn mathematics in daily classroom teaching.

Fortunately, I encountered my later co-operator, an experienced teacher who participated in my course for master students. One day after I discussed with her about how to access a truly authentic classroom and whether or not we could co-operate on such research, she promised me and provided me with a lot of related information. And later on, she figured out to videotape with the permission from the authority concerned her one-unit lessons focusing on proof in geometry by herself without any observation interruption. One week later, she finished the collections of her lessons so that I could make an observation and analysis on those authentic lessons. 


\subsection{Analysis Method}

For the analysis, I had to figure out what kind of analysis tool could be used to indicate how students learn in the classroom. After considering the two potentials of both capturing the typical feature of Chinese classroom-teachers' dominating talk and excavating students' understanding in classroom teaching, I selected and redeveloped the discourse analysis as a perfect method to deal with my research data (Wells, 1999).

\subsection{Discourse Pattern}

Clearly, the analysis results showed that the discourse in the classroom teaching was characterized by such a pattern as 'teacher question-students response-teacher feedback' which almost occupied the complete process of classroom teaching. In particular, for most time, all the students responded to the questions raised by the teacher with one voice without "differences" (Smith, 1991, p. 203). The undemocratic pattern was further illustrated by Gates and Vistro-Yu (2003) as dominant teaching method (chalk and talk), direct instruction, teacher-centered and transmissive teaching and dominant form communication (teacher talk).

In order to understand the role the students played in the discourse, I unpacked the discourse pattern. It was found that each of teacher's questions subsequently served as a scaffold to help students to solve the problem (Wang, Zuo, \& Lu, 2012). If they could answer those questions correctly, students would succeed in building the proof route to the geometrical problems. Obviously, it was not true in this promising finding that the students had made a passive acceptance of the teachers' own proof steps to the problems in the teacher-dominating discourse (Huang, 2006). In fact, the students participated in building the proof route and figured out the key answers for each step to those targeted geometrical problems. Therefore, this might lead us to understanding the reason why Chinese students could have a deep understanding of what they learned in such seemingly dominated lessons.

However, it is now clear to know that the teacher's questions could be served for sure to require students to fill out limited gaps. Given the specific contexts, few possibilities remained for students to answer the questions due to the limitation of such gaps (Watson, 2002). Therefore, the deep understanding of setting up the proper proof route to the geometrical problems is "objected, controlled, predicted, and manipulated" (Jardine et al., 1997, p. 257).

\subsection{Individual Attention}

In addition to the discourse pattern, it was revealed that the scenario of fixing individual student's problem was another feature emerging from the lessons in question. Except for the students' unison responses to the teacher's questions in the classroom teaching, the teacher also required individual student to answer a few questions. For example, in one period of a lesson, she asked a girl student to give out the reason why two edges were parallel in a graph. Then the student adopted an indirect way to approach the presumed proposition. However, what she expected was not the complicated approaching process the girl provided but a concise one, so the teacher asked another student for a better way to replace hers. Eventually, the complicated approach was "fixed" (Jardine et al., 1997, p. 260) by another better one. And furthermore, the teacher even checked out whether or not the student had understood that better way in the following discourse. However, at that time, according to my analysis, I took the above scenario as a positive case and made the appraisement that the teacher not only had encouraged the whole class to participate in the discourse with unison responses but paid a close attention to individual student's response as well. Was it not a very passive way? It was true that I appreciated that the teacher was "fully able to act, to help, to remedy, to repair, to intervene, with all the energies requisite of setting things right" (Jardine et al., 1997, p. 260) for whole class and individuals.

In 2013, an article about my analysis result was presented in an international conference (EARCOME6) in Thailand (see Wang, Zuo, \& Lu, 2013) and at that time, much attention to my research method in it was paid by the scholars from the world. Thus, I was so delighted at my best academic performance in mathematics education that my research interest was firmly and eventually set in the analysis on classroom teaching.

As a matter of fact, the way I analyzed the lessons was also the way of my understanding of research and of my inquiry for research meaning. Clearly, I was so heavily reliant on the method of the discourse analysis in my research that my understanding of classroom teaching depended only on the information gathered from the coding process in the analysis. Certainly, such information was purely technical meaning rather than an interpretation in a hermeneutic notion of understanding (Jardine, 2000; Smith, 1991). Thus, my research was a process of information gathering based on a certain method (Jardine, 2000). However, my understanding of classroom teaching and my way of doing research were shaken by the following event.

\section{Students' Learning in Classroom Teaching}

One month ago, I had a chance to observe a video of mathematics classroom teaching about $1 \div 2 / 3$ for Grade 5 in a seminar organized by a Professor in Canada. 


\subsection{Is the Teacher Working Conscientiously?}

The classroom in the video was organized very well with three boards on the different walls and students grouped at different round tables. It was apparent that such setting was potential to stimulate "conversation" (Jardine et al., 1997, p. 215) in the classroom teaching. However, at the beginning of the lesson, the teacher sat on a table among students. How could she sit on a table? In China, no teacher at any level school can do that at any time in the classrooms. Was she not very serious? I thought about this question and continued my observation.

\subsection{Is It a Normal Lesson?}

And then, the teacher started to explain the lesson task-calculating $1 \div 2 / 3$ by a way of making sense. In other words, students needed not only to get the answer but also to reasonably explain how they got it. I began wondering: "Don't Grade 5 students know how to calculate faction division?" Generally speaking, it is so easy to get the answer by using procedural knowledge: dividing a number is equal to multiplying the reciprocal number as

But does this make sense?

$$
1 \div \frac{2}{3}=1 \times \frac{3}{2}=1 \frac{1}{2}
$$

Interestingly, no student used such kind of procedural knowledge in solving the problem. After students articulated their answers, two answers were present: one was $1 \frac{1}{2}$ and another 6 .

Then the teacher asked four volunteer students to interpret their different approaches before the whole class. As for the answer

$$
1 \frac{1}{2}
$$

students gave three kinds of different ways of making sense. One way was circles dividing (discrete model), another one number line (continuous model) and the third one number sentence. Was it amazing? Yes, indeed. And moreover, whether or not each interpretation was reasonable was largely dependent upon "agreement of people to consent to them" (Smith, 1991, p. 197) rather than the teacher's delivering as an authority (Smith, 1991). From then on, I realized that students really understood the meaning of $1 \div 2 / 3$.

In addition, the answer ' 6 ' was obviously wrong in the eyes of the teacher. However, she took up "the difference not as a problem to be solved" (Smith, 1991, p. 203) and "fixed and intervened" (Jardine et al., 1997, p. 260), invited a girl whose answer was 6 to explain her thinking before a board, and listened to her as other students did. The girl was then one of them and, often more disturbingly for some of teachers as the Chinese teacher, the teacher, too, was one of them (Jardine et al., 1997, p. 257).

As a matter of fact, the teacher was so serious that she treated the fraction division interpretively to "engage with her children as fellow travelers, not only as objects to be controlled, predicted, and manipulated" (Jardine et al., 1997, p. 257) as that Chinese teacher had done.

After having finished the observation of the video, we were encouraged to air our own views about the lesson. My first question came into my mind about whether or not it was a normal classroom teaching. From my perspective, a lesson should have a clear planed knowledge goal with which students need to obtain from the classroom teaching rather than to solve a simple arithmetic problem.

During our later discussion, I came to realize that my question was seemed to be "humiliated" (Jardine et al., 1997, p. 256) by the interpretation of "what is at work" (Smith, 1991, p. 200).

\subsection{What Does Students' Understanding Mean?}

The truth in students' understanding of fraction division was not to memorize a procedure but a meaning of making sense for them. More importantly, the meaning was not imposed by the teacher but a conversation or dialogue within which teacher was a part other than dominating or orientating the discussion (Fairfield, 2010; Jardine, 2000; Smith, 1991). It is so obviously different from the teacher-dominant discourse in Chinese classroom. My understanding of the transmissionist thinking in Chinese classroom was challenged by the subjective meaning-making process of learning and knowledge construction which situated the learner at the center of the web of interpretation (Varney, 2009).

I began my doubt about whether or not the predetermined and directed understanding without any differences was regarded as real understanding in Chinese classroom teaching. If knowledge or information is handed over to children, even if children participate in the classroom discourse in certain way such as unison response, they will have nothing to say, and what the teacher, I too, has to say has already been said (Jardine, 2000, p. 131). Thus, understanding is not to be educed for students as well as for the teacher. 


\subsection{Where Could You Find the Teacher' Mathematics for Teaching?}

My response to the teacher's mathematics for teaching was centering on the learning task she had arranged. It was seen that the task of $1 \div 2 / 3$ was just good to stimulate students' exploration of fraction division because its conciseness of related manipulation could indicate the essential meaning of fraction division. Therefore, the task was thought of as a quite apt arrangement for students at Grade 5.

Another response from my colleagues was focusing on the teacher's confidence in facilitation of inviting different voices from students.

The third one was highlighting that the teacher could precisely understand students' variety of solution models, which was indicative of her ability to think mathematically.

Still, there were more responses...

\subsection{Why Are Students Not Afraid of Communication?}

I noticed an above-mentioned situation in which a girl got different answer 6 and was invited to demonstrate her thinking before the class. In fact, her answer was apparently wrong. But to my astonishment, she was not hesitant to show her way even if there already had been disagreements from other students with her answer. This scenario rendered me to consider why she was not afraid of feeling embarrassed once her answer was wrong. Responding to this, the professor who held the seminar explained that it might be resultant from the different classroom culture which did not settle everything once and for all but for the "profound pedagogical purpose of affirming the way in which present arrangements always border on and open onto" (Smith, 1991, p. 203) different voices.

Certainly, it is possible to generate or create more conversations about the lesson (Jardine, 2000) to "educe understanding" (Jardine, 2000, p. 116) of students' learning on fraction division. In fact, my colleagues required to continue the conversation with the passage of the scheduled time of seminar. Through the seminar, I realized that this was a different inquiry of classroom teaching from mine. Isn't the way of understanding classroom teaching hermeneutic inquiry? Indeed, the way of inquiry could help me not only to understand the "truth" (Jardine, 2000, p. 116; Jardine et al., 1997, p. 264) of the lesson but also to reflect my research as I have set.

\section{Discussion}

As for my research orientation, the lessons were considered as an analytical object to be analyzed by using discourse analysis-so called reliable tool as I have ever applied. Thus, the information and conclusions I have acquired was "obedient" to the method (Jardine, 2000, p.116). Therefore, my analysis of the lessons was not designed to educe the possibilities of understanding, but assumed only one possibility of its ground (Jardine, 2000, p. 116) and meanwhile was desired to render the dilemma "objectively presentable" (Jardine, 2000, p. 120) rather than to deeply recognize its "language, culture, history" and discourse way in which Chinese mathematics classroom teaching was "irremediably conditioned and contextualized by such phenomena" (Jardine, 2000, p. 121). The mark of good interpretative research is not in the degree to which it follows a specified methodological agenda, but in the degree to which it can show understanding of what it is that is being investigated (Smith, 1991, p. 201).

In other words, the hermeneutic imagination constantly requires what is at work in practices in order to "facilitate an ever-deepening appreciation of that wholeness and integrity "of the practices which "must be present for thought and action to be possible at all" (Smith, 1991, p. 197). In classroom, "interpretation is a dialogical activity" (Sotirou, 1993, p. 370). Otherwise, understanding will not be educed and "there was nothing more to be said about it" (Smith, 1991, p. 200).

Is hermeneutics for me? Yes, I think so. It is for me with regards to students' understanding of the fraction division; it is for me with regards to the research on classroom teaching as well. However, I am still on it from perplexity to confirmation to query about ...

\section{Acknowledgement}

The research is funded by Humanities and Social Science Research Project of the Ministry of Education, P.R. China. No. 13 YJC880075.

\section{References}

Fairfield, p. (2010). Education, Dialogue and Hermeneutics. London: Continuum International.

Fan, L., Wong, N. Y., Cai, J., \& Li, S. (2004). How Chinese Learn Mathematics: Perspectives from Insiders. Singapore: World Scientific Publishers. http://dx.doi.org/10.1142/9789812562241

Gates, P., \& Vistro-Yu, C. P. (2003). Is mathematics for all? In A. J. Bishop, M. A. Clements, C. Keitel, J. Kilpatrick, \& F. K. S. Leung (Eds.), Second international handbook of mathematics education (Vol. 1, pp. 31-73). Dordrecht, the 
Netherlands: Kluwer. http://dx.doi.org/10.1007/978-94-010-0273-8_3

Huang, J. (2006). The international comparison in mathematics classroom: Methodology, discovery and enlightenment. The Proceeding of annual conference of the National Research Association of Teacher Education. http://math.fjnu.edu.cn/zxsx/mathedu2006 (March 10, 2015 ).

Jardine, D. W. (2000). Reflections on education, hermeneutics, and ambiguity: Hermeneutics as a restoring of life to its original difficulty. "Under the tough old stars." Ecopedagogical essays (pp.115-132).Brandon: The Foundation for Educational Renewal.

Jardine, D. W., Graham, T., Friesen, S., \& Clifford, P. (1997). In his own hand: Interpretation and the effacing of the scribe (ch. 18). D. W. Jardine, S. Friesen \& P. Clifford. Curriculum in Abundance (pp.247-263). Mahwah, NJ: Lawrence Erlbaum Publishers.

Smith, D. G. (1991). Hermeneutic Inquiry: The hermeneutic imagination and the pedagogic text. In E. Short (Ed.) Forms of Curriculum Inquiry (pp. 187-209). Albany, NY: SUNY Press.

Sotirou, P. (1993). Articulating a Hermeneutic Pedagogy: The Philosophy of Interpretation. Journal of Advanced Composition, 13(2), 365-380.

Varney, J. (2009). From hermeneutics to the translation classroom: a social constructivist approach to effective learning. Translation \& Interpreting, 1(1), 27-43.

Wang, X., Zuo, X., \& Lu, C. (2013). The teaching strategies of promoting students' understanding in geometric proofThe perspective of developing Chinese localized mathematics education. In M. Inprasitha (Ed.), Proceeding of the 6th East Asia Regional Conference on Mathematics Education (EARCOME6) (pp. 214-223). Khon Kaen, Thailand: Center for Research in Mathematics Education (CRME).

Watson, A. (2002). Uses of unison responses in mathematics classrooms. Research in Mathematics Education, 4(1), 35-49. http://dx.doi.org/10.1080/14794800008520101

Wells, G. (1999). Dialogic inquiry: Towards a sociocultural practice and theory of education. Cambridge, Cambridge University Press. http://dx.doi.org/10.1017/cbo9780511605895

This work is licensed under a Creative Commons Attribution 3.0 License. 